\title{
La utopía conceptual feminista y el discurso literario: dos novelas de Roxana Pinto ${ }^{1}$
}

\section{(Conceptual Feminist Utopia and Literary Discourse: Two Novels by Roxana Pinto)}

\section{José Francisco Bonilla Navarro²}

Universidad Nacional, Costa Rica

\begin{abstract}
Resumen
Se analiza la representación literaria de los modelos femeninos presentados en dos novelas de Roxana Pinto, desde el paradigma teórico-metodológico que ve el planteamiento feminista como un proceso en construcción en el que pueden incorporarse las contradicciones y el respeto por la diferencia como elementos constitutivos de su propia construcción ontológica. Se acude al concepto de las heterogeneidades no dialécticas, concepto que reafirma la complejidad de los modelos femeninos presentados en los textos. El artículo hace hincapié en que los modelos de feminidad son, en su mayoría, contradictores y complejos.
\end{abstract}

\begin{abstract}
An analysis of the literary representation of feminine models in two of Roxana Pinto's novels, is carried out from the perspective of the theoretical and methodological paradigm which views the feminist position as a process in construction, in which contradictions and respect for difference can be included as components of their own ontological construction. Mention is made of the concept of non-dialectic heterogeneities, a concept which reaffirms the complexity of the feminine models presented in the texts. The article emphasizes that most models of feminineness are contradictory and complex.
\end{abstract}

1 Recibido: 22 de agosto de 2017; aceptado: 2 de mayo de 2018.

2 Escuela de Literatura y Ciencias del Lenguaje. Correo electrónico: josebn2910@gmail.com

LETRAS 63 (2018), ISSN 1409-424X; EISSN 2215-4094

Doi: http://dx.doi.org/10.15359/rl.1-63.4

www.revistas.una.ac.cr/index.php/letras 
Palabras clave: literatura centroamericana, novela costarricense, discurso feminista, Roxana Pinto

Keywords: Central American literature, Costa Rican novel, feminist discourse, Roxana Pinto

A partir de la década de 1960, la literatura centroamericana empieza a proyectarse como un discurso al que acuden voces que en épocas anteriores estaban silenciadas. De esta forma, durante la década de 1970 comienzan a publicarse textos de índole policíaca, novela negra, e incluso las novelas cuyas temáticas giran en torno a la homosexualidad. Manuel Puig es ejemplo recurrente dentro de este último campo. En el contexto de Centroamérica, producto de las experiencias guerrilleras se escriben textos como el de Omar Cabezas, La montaña es algo más que uno inmensa estepa verde (1982), o la de Marco Antonio Flores, Los compañeros (1976), cuyo referente inmediato es la guerrilla guatemalteca. Sin embargo, no es su apología heroica ${ }^{3}$; por el contrario, un acercamiento a los procesos revolucionarios centroamericanos como acontecimientos contradictorios y antagónicos a los gobiernos elitistas pseudo-democráticos a los que se oponían en las distintas naciones de la región. Asimismo, textos testimoniales como el de Rigoberta Menchú ${ }^{4}$ reafirman la apertura discursiva del quehacer literario en Centroamérica durante este período.

La inclusión de la mujer en el discurso literario constituye otro de los hitos sobre los cuales se reafirma esta apertura discursiva de la literatura centroamericana. Puede hacerse desde proyectos tan diversos como la participación femenina en los mismos procesos revolucionarios centroamericanos: Gioconda Belli, en Nicaragua; o bien desde preocupaciones ancladas en la búsqueda de modelos feministas centrados en la experiencia femenina, me remito a la poesía de

3 Beatriz Cortés, «Memorias del desencanto: el duelo postergado y la pérdida de una subjetividad heroica», Hacia una historia de las literaturas centroamericanas. Intersecciones y transgresiones: propuestas para una historiografia literaria en Centroamérica (Guatemala: F y G Editores, 2008) 259-280.

4 Rigoberta Menchú y Elizabeth Burgos, Me llamo Rigoberta Menchú y así me nació la conciencia (Habana: Casa de las Américas, 1983). 
la guatemalteca Ana María Rodas, y Daisy Zamora o Michel Najlis. En esta vertiente se circunscribe el presente estudio, en particular, el análisis y comparación de los modelos femeninos de dos novelas de Roxana Pinto: Donde ellas (2004) e Ida y vuelta (2016) ${ }^{5}$, ambas presentan un discurso femenino, cuyo foco principal es un personaje preocupado por aspectos sociales y políticos diversos de una sociedad contemporánea marcada por la nostalgia y cierto desencanto existencial.

Textos literarios como los propuestos para el análisis, constituyen puntos de enunciación de discursos, en este caso con presupuestos feministas, que intentan mostrar la intersubjetividad que compone a la compleja sociedad actual; es decir, se sirven de una cierta herencia socio-histórica propiciada por la apertura discursiva que emerge a partir de la década de $1960^{6}$, como ya lo he señalado previamente.

Pareciera que la crítica literaria feminista en Costa Rica no ha sido tan profusa como en otros lares de Hispanoamérica, si se piensa en críticas como Nelly Richards ${ }^{7}$. Mucha de la crítica literaria costarricense femenina se ha detenido en asuntos teórico-metodológicos de la historiografía literaria centroamericana, pero se han preocupado por la teorización sobre los planteamientos feministas actuales.

Algunas escritoras como Carmen Lyra han sido objeto de estudio desde las perspectivas feministas. En Narrativa de mujeres en Costa Rica: personajes femeninos en los "Cuentos de mi tía Panchita», Marcia Ugarte Barquero, de la Universidad de Barcelona, presenta un análisis, amparado en postulados feministas, sobre el papel que cumplen los personajes femeninos en la obra citada. Concluye que se presentan imágenes femeninas que rompen con los modelos tradicionales del patriarcado ya que muchos de los personajes reaccionan

5 Roxana Pinto, Donde ellas (San José: Ediciones Perro Azul, 2004); y Ida y vuelta (San José: Uruk Editores, 2016).

6 George Igger, La historiografia del siglo xx. Desde la objetividad cientifica al desafio postmoderno (Chile: Fondo de Cultura Económica, 2012).

7 Nelly Richard, «Feminismo, experiencia y representación», Revista Iberoamericana. LXII, 176177 (1996) 733-744. DOI: https://doi.org/10.5195/reviberoamer.1996.6256. 
ante la injusticia social y también desechan la pasividad como una condición característica de la mujer ${ }^{8}$.

María Eugenia Acuña emprende un análisis de los personajes femeninos proyectados en la obra de Carlos Gagini. A partir del contexto histórico de la obra del autor, Acuña describe la construcción que realiza Gagini. Mas que un análisis de una escritura femenina determinada, se trata de una descripción de la representación sobre mujeres en la literatura de Gagini. La autora plantea que

Teniendo en consideración las afirmaciones anteriores, se puede indicar que Carlos Gagini es uno de los precursores de aquella literatura que busca un cambio en la consideración social de la mujer. Con ideas avanzadas para su tiempo, y gran valentía, adoptó la defensa de un sector de mujeres costarricenses en procura del cambio a través de la educación integral y del trabajo dignificador?

Más que una preocupación por analizar discursivamente las letras femeninas de la época, existe un esfuerzo por mostrar a un escritor costarricense de principios de siglo xx como una excepción a las valoraciones del contexto histórico que regularon la participación femenina en los diversos campos de la vida pública y privada en el país. Hólmfríður Garðarsdóttir ${ }^{10}$ se ha referido a la literatura costarricense de escritoras como Rossi, desde la perspectiva epistemológica de la subalternidad. A diferencia del estudio anteriormente citado,

8 Marcela Ugarte Barquero, Narrativa de mujeres en Costa Rica: personajes femeninos en los "Cuentos de mi tía Panchita». Trabajo de investigación para optar por el Máster en Lengua Española y Literatura Hispánica (Universidad de Barcelona, 2011) 37.

9 María Eugenia Acuña, «La imagen de la mujer en la literatura costarricense de principios de siglo», Letras, 23-24 (1991) 149-159 (158).

10 Hólmfríður Garðarsdóttir, «La mujer de color: identidad y la diáspora global de la subalternidad», Eds. María Clara Medina, Edmé Domíngez y Rosalba Icaza Garza, Género y globalización en América Latina: décimo aniversario de la Red Haina (1996-2006), actas del Simposio-taller celebrado en el Instituto Iberoamericano de Gotemburgo en junio de 2006, (Red HAINA. Instituto Iberoamericano e Instituto Vidgís Finnbogadóttir de Lenguas Extranjeras de la Universidad de Islandia, 2007) 171-182. Consultado en <https://hispanismo.cervantes.es/publicaciones/generoglobalizacion-america-latina-decimo-aniversario-red-haina-1996-2006> y disponible en $<$ https:// gupea.ub.gu.se/bitstream/2077/.../gupea_2077_9971_5.pdf>. 
describe la escritura femenina, ya que se concentra en la narrativa de Ana Cristina Rossi. Su objetivo es «determinar la presentación de personajes masculinos y femeninos. Además [...] pregunta si la globalización de la subalternidad influye sobre la búsqueda de la identidad perdida de la mujer de color» ${ }^{11}$. La interseccionalidad que adhiere al estudio realizado hace que los hallazgos a los que llega sean aún más interesantes, porque debe hacerse hincapié en que el movimiento feminista no es una construcción monolítica y estática; no puede asumirse de una manera universal, ya que las condiciones de existencia de las mujeres varían hasta por causas sociales, económicas y de clase. No es casual que al final de su artículo, el autor se refiere a las identidades que construye Rossi en su novela; son identidades encarnadas por los sujetos femeninos.

En este trabajo, la categoría del feminismo se toma desde los planteamientos de Teresa de Lauretis; sin embargo, será necesario tomar un concepto propuesto por Antonio Cornejo Polar (1996): las heterogeneidades no dialécticas, porque se parte de la hipótesis de que el planteamiento feminista está condicionado por una fragmentación en cuanto a su capacidad de acción en los ámbitos sociales a los que alude. En otras palabras, hay espacios dentro de los cuales el feminismo puede aflorar y otros en que no; esto último lleva a que $l o$ feminista no se reduzca a un planteamiento dicotómico; sino, más bien, que deba conceptualizársele como un proceso que se construye y se desconstruye y, dentro del cual, la contradicción y las inconsistencias en cuanto a la experiencia femenina serían partes constitutivas de su condición ontológica.

Teresa de Lauretis, en «La tecnología del género», para conceptualizar lo feminista, parte de un abandono total de la relación entre género y el concepto de diferencia sexual, porque ella considera que, entre otros factores, dicha noción descomplejiza la ontología misma de la mujer como sujeto activo de una sociedad específica, además

11 Garðarsdóttir, p.171-172. 
de crear una falsa imagen universal de la misma ${ }^{12}$. Al abandonar la noción del género anclada en una diferenciación sexual, Lauretis se encauza en la temática de la representación, por ello es que lo concibe y lo crea a través de tecnologías dadas por ciertos sectores sociales del medio que circunda al sujeto. Apunta Lauretis:

El término género es, en efecto, la representación de una relación, ya sea que pertenezca a una clase, a un grupo o a una categoría. El género es la representación de una relación, o [...] el género construye una relación entre una entidad y otras entidades que están constituidas previamente como una clase, y esa relación es la de pertenencia; de este modo, el género asigna a una entidad, digamos a un individuo, una posición dentro de una clase y, por lo tanto, también una posición vis-a-vis con otras clases preconstituidas. [...] Así, el género representa no a un individuo sino a una relación, y a una relación social; en otras palabras, representa a un individuo en una clase ${ }^{13}$.

Esta definición, según los cánones de la representación, permite concebirlo desde unos parámetros teóricos e incluso vivenciales que se encuentran caracterizados por la condición de proceso; o sea, el sujeto feminista. Conforme con este planteamiento, se concibe como un sujeto en acción, que se va construyendo a partir del enfrentamiento con los diversos entornos de la sociedad a la que se enfrenta. No es, por el contrario, una postura que se asuma desde lo dicotómico o dialéctico, su análisis posee un nivel de complejidad mayor que el que sugieren estos últimos dos calificativos.

Aplicado a un ámbito discursivo literario, los sujetos femeninos de las obras escogidas para el análisis se mueven según estos patrones de configuración y construcción de lo femenino. Pareciera que en la narrativa contemporánea, en la escrita por mujeres específicamente, la

12 Teresa de Lauretis, «La tecnología del género». Technologies of gender. Essays on Theory, Film and Fiction (Londres: Macmillan Press, 1989) 1-30 (7).

13 De Lauretis, 10; el destacado es propio de la autora. 
idea de (re)construir pasados heroicos y mitologizaciones ${ }^{14}$ de ciertos personajes ha quedado desplazada más bien por preocupaciones de carácter estético-ideológicas; es decir, ha prevalecido un esfuerzo por dar, discursiva y vivencialmente, una poética de lo femenino, dentro de la cual la mujer es un sujeto social capaz de establecerse como tal; sujeto en el cual la diferencia y la contradicción no son aspectos que condicionen negativamente su existencia, al contrario, la reafirman como metonimias de una sociedad cada más compleja, y dentro de la cual los límites entre uno u otro fenómeno cultural se empiezan a tornar difusos.

La concepción del sujeto femenino en este trabajo se centra en el principio de que dicho sujeto «es uno no tan definido» ${ }^{15}$. Así, siguiendo a la misma autora, la teoría feminista debería encarnarse en «sujetos históricos gobernad[o]s por relaciones reales, que incluyen centralmente al género; tal es la contradicción sobre la que debe construirse la teoría feminista y su misma condición de posibilidad $»^{16}$. Para Lauretis, la condición feminista se genera a partir de una representación que es la construcción misma de los sujetos; sin embargo, dicha representación debe estar mediada por una capacidad de agencia que motive y propicie que dicha representación se aleje de las construcciones tradicionalmente patriarcales que se han hecho de los sujetos femeninos ${ }^{17}$.

Pareciera, entonces, que queda al margen toda conceptualización del feminismo que adopte una posición dicotómica con respecto a las relaciones sociales que se puedan tejer en el entramado social y contextual de los sujetos femeninos, pues esto correspondería con una visión utópica y mitologizante de los mismos sujetos, además que sería una concepción muy poco atinente para los patrones que rigen las relaciones humanas contemporáneas. En síntesis, esta visión

14 Cortés, 259-280.

15 De Lauretis, 16.

16 De Lauretis, 16.

17 De Lauretis, 33. 
utópica de las nociones del feminismo ha reducido la complejidad de los sujetos y la sociedad en la que se desenvuelven, pues las construcciones sobre el concepto de género que se han establecido se han amparado en las divisiones meramente sexuales ${ }^{18}$.

Las novelas de Roxana Pinto son ejemplos de este tipo de planteamiento, ya que posicionan a sujetos femeninos que entablan relaciones sociales con el medio que las circunda. Sin embargo, no son relaciones que se definen como unívocas y estáticas; al contrario, son muestras de experiencias contradictorias e inconsistentes si se quisiera tener en la experiencia femenina una fuente de análisis que genere las condiciones propias de diferenciación con respecto al patriarcado. Las protagonistas de ambas novelas, siguiendo a de Lauretis, no poseen capacidad de agencia plena y constante; más bien se presentan como personajes que afrontan el entorno con la idea de construir y buscarse ellas mismas como personajes feministas; tarea que, en ninguno de los casos, se completa; antes bien, afloran contradicciones e inconsistencias en las construcciones asumidas por la escritora. Esto último, desde la perspectiva teórica a la que se circunscribió este trabajo, no es argumento para calificar los textos como antifeministas; más bien ejemplifican la renovación ontológica de la que habla de Lauretis, pues reafirma, desde un plano discursivo, la existencia de opciones no dialécticas, de planteamientos cuya característica fundamental se codifica adoptando la diferencia como aspecto constituyente del mismo proceso de construcción feminista.

Antes del análisis, conviene una breve fábula de ambos textos, cuya trama es relativamente sencilla. En Donde ellas (2004), Pinto moldea a una mujer, Ela, periodista de El Imparcial, que decide, darle un giro radical a su vida. Busca su pasado a Junguaniquil, donde emprende una investigación sobre plantas medicinales. Vuelve a la ciudad para publicar su investigación. Toda la reconstrucción del pasado de la protagonista se efectúa mediante la relectura de un viejo diario de

18 De Lauretis, 1-30. 
adolescencia que encuentra en una antigua casa donde había vivido en Barrio Amón. En Ida y vuelta (2016), la narración es distinta: se trata de una novela que narra el viaje de Anadí, una costarricense que decide ir a prepararse en la Escuela de Bellas Artes de Francia; vive en Europa durante trece años; su estadía le permite al lector reconstruir París por medio de sus observaciones y sus pinturas. Al romper las relaciones laborales con la compañía de Laroche, regresa a Costa Rica. Ambas ciudades están conectadas en toda la narración; no obstante, a nivel discursivo, el papel del tiempo es crucial en la generación de sentido de ambos textos: tanto San José como París se tornarán ciudades del pasado, ciudades en las que la protagonista busca recrear los recuerdos de infancia vividos con sus familiares en una etapa anterior al tiempo de la narración; es decir al tiempo del presente de la protagonista.

Es en el plano discursivo en el que se centra este análisis, porque se ha venido insistiendo en un modelo feminista conceptualizado como una construcción y un proceso: el discurso, es forma, es construcción y representación de un fenómeno específico; casi inútil sería estudiar el corpus basándose en un análisis meramente temático, ya que disminuiría y hasta eliminaría la complejidad de los personajes construidos en ambas novelas.

Un primer aspecto por señalar es que, por la forma como se presentan en el desarrollo de la narración, tanto Ela (Donde ellas) como Anadí (Ida y vuelta) son personajes obsesionados por asuntos existenciales. En ambas novelas se abandona la idea de presentarlas al lector como individuos estáticos y monolíticos; incluso son personajes en formación que se irán estableciendo y moldeando de acuerdo con las circunstancias que enfrenten como sujetos femeninos.

En Donde ellas la autorreflexividad que caracteriza a Ela es un aspecto notorio incluso desde el mismo inicio de la novela.

Recostada sobre el sofá, Ela prácticamente desaparece hundida entre los almohadones $[\ldots]$ Tiene el libro recién salido de la editorial, que 
va a releer, en las manos. La última vez que lo leyó se convenció de que estaba permeado por los testimonios de mujeres de diversos niveles socioeconómicos. Era evidente. Algunas confesaban tener deseos apasionados, otras los prevenían y otras más tenían deseos imposibles y eternos... ${ }^{19}$.

Aquí se muestra un juego de metadiscursividad, pues Ela, como personaje de la novela escrita por Pinto, también está observando y analizando una novela recién publicada, novela que, el lector sabrá que se titula Donde ellas. Este fragmento permite configurar, al menos, tres tipos de sujeto femenino: a) aquellas mujeres motivadas por deseos apasionados, b) aquellas que los previenen y c) las que los viven como imposibles y eternos; es decir, como utopía inalcanzable por no decir, como irrealidades y espacios prohibidos, en los que la mujer ni siquiera se asume como sujeto. Mediante la configuración de un narrador omnisciente, se expresa la conciencia de la idea de «mujer», esto como categoría de unificación, cuyo patrón común está mediado por los tres tipos de sujeto descritos antes. Desde ese momento, mediante la voz narrativa se descomplejizan los modelos femeninos posibles y se los encasilla en una clasificación monolítica cuyo punto de enunciación es el pensamiento y análisis propio de Ela como personaje.

Como segundo aspecto, el asedio que provocan en el personaje los interdiscursos de carácter moral, ético y religioso, deja manifiesta la condición ambivalente del personaje construido en la primera novela de la autora, en la que la madre de Ela encarna un discurso típicamente moralista, el cual, al entrar en contacto con la protagonista, desnuda las vertientes en las que se subdivide el personaje. Así, apunta Ela:

Mamá duerme, yo soñaba con ÉL cuando sentí ese golpe sobre la cabeza y oí el gran estrépito; enciendo la luz y descubro el cuadro de

19 Pinto (2004) 7. 
la Virgen María en el piso, siempre estuvo centrado en la pared del dormitorio donde mi sombra y yo caminamos.

Ahora sé que soy dos elas.

Una que recita las palabras, que dice mamá, de memoria, y otra con un cuerpo hecho de carne que se estremece, pechos respingados y caderas que se mueven por cuenta propia

La parte alta de mi cuerpo es pura. La parte baja, aún sin descubrir, es virgen ${ }^{20}$.

Al respecto, la ambivalencia del personaje radica en la configuración de dos individuos dicotómicos: uno reprimido por el discurso moralista y conservador de la madre, el otro caracterizado por cierta libertad de gozar placenteramente de su cuerpo y la vivencia de la sexualidad sin ninguna represión. Dicha dicotomía se elimina para dar paso a la existencia de un personaje cuya representación de la experiencia femenina está marcada por la unión de ambos individuos; es decir, Ela, como modelo femenino de Donde ellas, se asume como ambas mujeres, pero también toma decisiones que la dotan de cierta agencia y, por consiguiente, de cierta independencia con respecto al modelo moralista de la madre.

En Iday vuelta, la experiencia de Anadí se circunscribe a este tipo de situaciones: entre una cotidianidad «normalizada» dentro de la que se supone debería estar una mujer «normal» y los supuestos contextos de ruptura o prohibiciones que, por acceder a ellas, se reafirman como espacios de no existencia para las mujeres. También como producto de un proceso autorreflexivo, apunta Anadí, «acepto que no soy una unidad. Cuando le conté a mamá que ahora pinto y escribo comentó que solo la gente inestable brinca, como un colibrí, de un arbusto a otro. Además que eso me iba a quitar tiempo para entablar una buena relación de pareja ${ }^{21}$. El motivo del emplazamiento de la mujer en un espacio y discurso específicos ya no lo pinta la prohibición del goce y el placer corporal; sino más bien la necesidad de establecer una 
relación de pareja como símbolo de confirmación y revitalización de una institución social que ha sido clave en las sociedades latinoamericanas por largo tiempo: la familia.

Anadí, más que Ela, hace de su condición femenina una experiencia contradictoria y dinámica a la vez. Como individuos de una sociedad moderna, fragmentada y diversa, no pueden circunscribirse como una entidad monolítica y cuadrada, sino como una subjetividad que entra, hasta cierto punto, en pugna con el medio que la circunda. Por ello, el de estrechar relaciones con ese universo inmediato se produce una sensación de disconformidad y desequilibrio ejemplificados en la siguiente cita.

La gente ante la cual me presento como una persona que lee, reflexiona, callejea por París y se mueve en una caótica soledad cuando pinta y escribe, posiblemente tendrá sus propias versiones de mí [...] Tener una naturaleza múltiple y ramificarme en diversas Anadíes, acaso sea mi marca de identidad, o mi falta de ella ${ }^{22}$.

Ela y Anadí son representaciones de sujetos femeninos ambivalentes, situados entre opiniones dicotómicas que rigen un mundo polarizado entre lo típicamente masculino y lo típicamente femenino, pero que, desde la imagen feminista a la que recurre Lauretis, a su vez son personajes que no caen en el juego de la polarización; por el contrario, se mueven en una especie de continuum social en el que la experiencia las constituye como sujetos femeninos donde la agencia está dada intermitentemente. Si esto es así, entonces ¿cuáles son los espacios donde se puede enmarcar dicha agencia femenina?

En comparación con los espacios en los que se anula el sujeto femenino, aquellos en los que logra alcanzar una capacidad de agencia son más reducidos. En Donde ellas, Ela parece adquirir agencia en el momento que decide abandonar la ciudad de San José e irse a Junguaniquil; pero es solo una sospecha que genera la lectura inicial

22 Pinto (2016), 47-48. 
del texto, ya que lo que comprueba luego es lo contrario: realmente el viaje propicia la aparición de una serie de imágenes asociadas a un modelo patriarcal tradicional, dentro del cual se autorrepresenta como un sujeto vulnerable. En esta novela, la capacidad de agencia, casi nula, se observa en pequeños eventos intermitentes como la decisión de abandonar la ciudad y la ruptura con Enrique, su jefe en El Imparcial. Muestra de esa agencia parcializada se expresa en la siguiente cita:

Ela no quiere seguir dependiendo de él. Tampoco desea gastar más tiempo cambiando las cosas de lugar, sacudiéndolas, sufriendo porque puedan romperse o perderse. Desea ir al bosque a estudiar las plantas medicinales, a hundir sus uñas en la corteza de los árboles y tocar sus vetas. Desea también ir de cacería, pero no de animales. Ir a cazar, desplumar, despellejar, descuartizar, con locura, sus miedos ${ }^{23}$.

Aquí narración configura una Ela preocupada por abandonar los lugares comunes que el patriarcado le ha asignado a la condición de lo femenino. Esta reafirmación se cristaliza en la presentación del deseo de la protagonista y su posterior cumplimiento; tal capacidad de decisión queda cuestionada al momento cuando se interioriza el vacío que genera la ausencia del modelo masculino. Sin embargo, dicho aspecto será tratado más adelante, como parte de aquellos espacios donde este modelo se rompe.

En Ida y vuelta, estos espacios de emancipación femenina se presentan en un nivel intelectual y artístico. Desde estos campos la mujer, específicamente, Anadí, adquiere una independencia y un reconocimiento propios en el ámbito parisiense en el que se desenvuelve; sin embargo, más que su capacidad artística, la verdadera agencia del personaje se encuentra justo al final de la novela, cuando el personaje explica cuál fue el motivo de su regreso a Costa Rica:

Como muralista, en París no tengo futuro. Antes de convertir el arte en una mercancía, renuncié. Jamás iba yo a sustituir la selva que

23 Pinto (2004), 62. 
muere y se regenera y que he pintado con tanto amor, por una selva artificial, decorativa, sin carácter, sin compromiso ni toma de posición... Monsieur Laroche esperaba que yo me traicionara por ver mi nombre escrito al pie de un mural, en una calle céntrica de París ${ }^{24}$.

La decisión de partir de la capital francesa condensa metonímicamente el pensamiento de la protagonista con respecto a lo artístico y lo ecológico. Sin embargo, la narración configurará espacios, al igual que en la primera novela, donde dicha capacidad de agencia se ve reducida y hasta anulada como aspecto constitutivo de lofemenino. Llamo espacios de inconsistencia en la construcción de los modelos femeninos a aquellos sucesos o circunstancias que propician la representación de la mujer según imágenes tradicionales con las que la tradición patriarcal las ha asociado y las ha «integrado» dentro de la sociedad actual. En adelante se enumerarán aspectos que permitan evidenciar las contradicciones y las inconsistencias según las cuales los personajes femeninos de ambas novelas quedan anulados como sujetos capaces de entablar relaciones intersubjetivas sin violentar los principios de libertad que ello conlleva. Es decir, estas constituirán espacios donde la mujer se codifica a través de relaciones de subordinación y dominación con respecto a otros discursos de la sociedad, llámense patriarcado, colonialismo cultural, o bien, estereotipos preconcebidos de la condición femenina.

En un primer acercamiento, en las novelas se reproduce un modelo femenino cuestionable al momento en que las protagonistas de ambos relatos se conciben como un objeto observable y deleitante para el discurso patriarcal representado, en estos textos, por la figura del varón. Así, en Donde ellas, Ela desea que se le reconozca presencia e importancia a partir de las opiniones que pueda generar, en el otro (modelo de masculinidad hegemónico) su exhibicionismo corporal.

24 Pinto (2016), 234. 
De adulta le continuó gustando atraer la mirada masculina, pero la rechazaba de inmediato, desviando tímidamente los ojos. A pesar de que los zapatos puntiagudos y de tacón alto que comenzaron a usar las mujeres en el siglo XVII le torturaban los pies, los llevaba a diario a la oficina. Los tacones altos la hacían sentirse más llamativa. Al caminar, acentuaban el movimiento lateral de sus caderas.

$[\ldots]$

Durante unos segundos la ilusión es completa y percibe de nuevo esa mirada masculina capturar una a una sus protuberancias y sus pliegues. Su cuerpo con la pelvis ancha y los pechos frondosos es una promesa de fecundidad, aunque quizás no sería tan seductora, si no hubiera en ella además algunos rasgos masculinos: una nariz grande y unos brazos delgados pero un tanto musculosos ${ }^{25}$.

Según esto, el personaje femenino se anula por completo en tanto sujeto humano, ya que se plantea como un objeto y, al hacerlo, pierde toda agencia posible que pueda ser asignada por medio del discurso, ya que se trata de una representación de lo femenino, pero que bien podría ser llevado a la realidad extratextual de las mujeres en la actualidad. Para reafirmarse como objeto observable, Ela, acude a la caracterización propia desde un espacio que ha sido aprovechado por el patriarcado para justificar la asimetría machista; es decir, se «construye» a sí misma desde la noción binaria de fecundidad-maternidad. Esto último refuerza su condición de objeto deshumanizado y, por tanto, incapaz de regirse como sujeto independiente.

Otro de los espacios de anulación de la agencia femenina lo constituye el arquetipo de la femme fatale. Esta construcción discursiva constituye un engaño bajo el cual se han sustentado muchas representaciones de los modelos femeninos que pretenden alcanzar un estatus feminista. Es engaño, pues muestra la lógica según la cual se pretende rebasar y superar, así como evadir, la imagen de vulnerabilidad y dependencia que ha creado el discurso patriarcal sobre la mujer. Ofrece la visión de una mujer falsamente empoderada y

25 Pinto (2004), 133-134. 
capaz de generar daño y perdición al otro (modelo tradicionalmente subyugador); sin embargo, al momento de ejecutarlo lo que se crea es una duplicación que iguala la posición de ambos géneros en tanto las relaciones de poder que se establezcan, asumiendo, así, la lógica patriarcal bajo la etiqueta de un empoderamiento femenino. Véase la siguiente cita.

Veo por primera vez a Gustave en el ascensor. Es elegante. Bien vestido. Tiene pelo liso de un rubio azafranado y unos ojos verdosos que desvisten con la mirada. En el dedo anular lleva un anillo en forma de serpiente, que me evocó la selva y, a la vez el paraíso perdido. Le tiendo mi tela de araña con pequeñas dosis de sonrisas, miradas y movimientos de cabeza en plan Hollywood. La charla nos llevó, irremediablemente, a intercambiar números de teléfono ${ }^{26}$.

Aunque no se circunscribe a un plano de lo femenino, la Anadí que construye Pinto en Ida y vuelta fracasa, en tanto sujeto latinoamericano estereotipado, en el momento de construirlo desde la concepción de un modelo infantilizado. Esto se muestra en el momento cuando Anadí observa por primera vez una nevada en París.

Hace ya tres meses que asistimos a clases, cuando al mirar hacia la ventana y ver por primera vez nevar, me levanto gritando: - ¡Niege!, ¡Niege!-. Genevieve me mira extrañada y con un aire de desaprobación. Nunca llegó a saber que en ese momento cobraba vida aquella tarjeta postal en blanco y negro con que mi padre acostumbraba marcar la página del libro que leía ${ }^{27}$.

La inconsistencia no radica en comunicar la emoción que siente el personaje por la caída de la nieve, ya que los centroamericanos carecemos de zonas donde haya nieve, sino en la manera cómo expresa el discurso del personaje. La intención narrativa reafirma las construcciones estereotipadas que han caracterizado la presencia de los latinoamericanos

26 Pinto (2016), 83. El destacado es mío.

27 Pinto (2016), 49. 
en los contextos de las metrópolis europeas. Discursivamente, la imagen que se representa está caracterizada por la presencia de la ridiculización y el rebajamiento (esto por medio de la infantilización que se hace del personaje) que sufre Anadí vista desde los ojos censuradores de la compañera francesa, Genevieve.

La feminidad representada en ambas novelas materializa otra de las inconsistencias al momento de establecer los vínculos sentimentales entre el modelo femenino y los patrones masculinos, pues las relaciones se codifican a través de relaciones asimétricas, donde se reafirma la hegemonía patriarcal sobre la mujer. En Ida y vuelta, el modelo femenino que se configura a raíz de la relación con Gustave está marcado por la presencia de la ilusión, la inocencia y el engaño. Estos factores delinean una subjetividad femenina que, desde los planteamientos teóricos del feminismo aquí esbozados, sería cuestionable y debatible. Señala Anadí:

Me siento ilusionada. Pronto esta ciudad me ofrecerá la oportunidad de bailar a pasitos cortos la Java, abrazada al cuello de Gustave, mirándonos a los ojos, y sintiendo cómo me agarra las nalgas para apretarme bien contra su cuerpo. [...]

Han pasado tres días y continúo llevando el celular conmigo a donde quiera que vaya. Marco su número de teléfono y luego cambio de idea. Finalmente lo llamo pero una voz automática me comunica que el abonado no está disponible en este momento, que vuelva a intentarlo más tarde. Temo que haber hecho el amor no haya tenido ninguna importancia para él; que haya sido un acto indefinido, vanal, que se evapora en poco tiempo ${ }^{28}$.

Al preguntarse Anadí, «¿Me habrá percibido como una persona digna de entregarle su amor?» ${ }^{29}$; la misma imagen se genera cuando coloca a Roberto Aguirol en un plano superior a ella misma, porque lo tiene por modelo de masculinidad inalcanzable. Si es necesario hacer

28 Pinto (2016), 87-88.

29 Pinto (2016), 157. 
referencia a la otra novela, en Donde ellas, la relación que se establece entre Ela y Carao es una muestra clara de este planteamiento, con el agravante de que es Carao, en esta novela, el personaje masculino que llega a completar y cumplir el anhelo de Ela de ejercer la maternidad; al hacerlo se constituye como la figura a la que incluso Ela agradece por brindarle su amor ${ }^{30}$.

El exotismo sexual como constituyente de la identidad de la mujer latinoamericana es el último de estos espacios de inconsistencias y contradicciones del modelo feminista representado por Pinto, específicamente en su segunda novela. Anadí constituye un antimodelo cultural con respecto a lo que representa Gustave como caballero francés. Aquí, los nombres y los gustos musicales constituyen metonimias de aquello que se establece como cultura, por un lado, y como contracultura, por otro. Al escuchar, en un restaurante al que sale a comer con Gustave, un merengue (ritmo musical ícono de la identidad latina), Anadí interpela a su compañero de la siguiente forma:

-Ah, este ritmo me fascina. Vamos a bailar, Gustave.

- No sé bailar eso.

- Lo único que hay que hacer es mover las caderas de adelante hacia atrás, de izquierda a derecha flexionando las rodillas, y girar hacia afuera y hacia dentro las puntas de los pies. Estos ritmos latinos me vuelven más despreocupada y sensual. Me evocan imágenes de labios fundiéndose los unos con los otros, pero a él no parecen afectarle tanto como a míri .

Se desarrolla un estereotipo femenino marcado por una hipersexualización de la mujer latinoamericana; estereotipo que, por la forma como está dispuesto en el discurso literario, se establece como contrapunto de la cultura francesa representada por Gustave.

En general, ambas protagonistas constituyen modelos femeninos analizados desde una conceptualización feminista anclada en

30 Pinto (2016), 160.

31 Pinto (2016), 84. 
representaciones maniqueas y estáticas: se convierten en modelos rechazados por una determinada parte de la crítica feminista contemporánea. Si se toma en consideración la opinión de Lauretis y la idea de abandonar posiciones dialécticas en el feminismo, se convierten en personajes, cuya representación de modelos femeninos se caracteriza por ceder espacios a la contradicción y la diferencia en tanto elementos constitutivos de la ontología feminista.

\section{Conclusiones}

De acuerdo con el desarrollo de este estudio se hace necesario entender que:

a. Para comprender la complejidad que representan los sujetos femeninos construidos en obras como las de Pinto, es indispensable abandonar una idea monolítica del pensamiento feminista, para dar paso a las contradicciones y los acercamientos paradójicos como aspectos que delinean las raíces ontológicas de este pensamiento.

b. El problema de lo feminista no se encuentra en lo representado, sino en la manera cómo se representan y construyen las relaciones entre los géneros coexistentes dentro de una sociedad determinada.

c. Comparado con el modelo femenino que Roxana Pinto construye en Donde ellas, el que presenta en Ida y vuelta es muy similar; sin embargo, la mujer tiene capacidad de agencia en el ámbito artístico, intelectual y político-ideológico. A pesar de ello, cuando se coloca en relación con los modelos masculinos sucede lo mismo que en la primera novela: se vuelve un sujeto pasivo y receptáculo.

d. Pareciera que en el campo de las relaciones socio-afectivas entre los modelos femeninos con los masculinos es que sigue residiendo una amplia gama de contradicciones que fortalecen 
las representaciones tradicionales de la feminidad; de ahí que en procesos como la maternidad, el matrimonio y la vivencia de la sexualidad, la mujer siempre desempeñe un papel marcado por la pasividad y subordinación a la figura patriarcal.

e. La visión que pretende dejar al margen la concepción del feminismo como un proceso constituye una versión utópica y mitologizante del feminismo como corriente de pensamiento. Al llevar a la experiencia este tipo de modelos dicotómicos se reduce la complejidad de los sujetos femeninos que existen en las realidades históricas específicas. 